DOI: https://dx.doi.org/10.26808/rs.ca.i10v5.02

International Journal of Computer Application (2250-1797)

Issue 10 Volume 5, September- October 2020

\title{
SOLVING THE POLYTECHNIC CLASS SCHEDULING PROBLEM USING INTEGER LINEAR PROGRAMMING MODEL
}

\author{
${ }^{1}$ Abdullahi A. A., ${ }^{2}$ Raji I. I. and ${ }^{3}$ Oyeniyi R. B. \\ Department of Mathematics and Statistics, \\ Federal Polytechnic Ado-Ekiti, Ekiti State. \\ 1 iiraji2007@gmail.com and ${ }^{2}$ ridous008@gmail.com
}

Abstract
This paper considers the problem of polytechnic course timetabling. In this problem, there are
set of courses, lecturers and classrooms. The objective is to assign schedule courses so as to
maximize the total preference of lecturer-course, lecturer-day and course-day. The problem
was formulated in the form of linear integer programming model. Using the model and
commercial software, the small sized instances are optimally solved. The model is solvable
by IP Solvers, and the result was presented from the IP formulation.

Keywords: Timetabling, Mathematical model, Cost coefficients.

\section{Introduction}

A scheduling problem consists of utilizing a set of limited resources to perform a set of tasks. One of the most important scheduling problems is educated timetabling (MirHassani, S. A. et al, 2013) .In classical educational timetabling problems, we need to assign a set of events (such as courses and exams) into a certain number of 'classroom-time' slots subject to set of different constraints [19]. Course timetabling is the process of assigning courses, rooms, students, and lecturers to a fixed time period, normally a working week, while satisfying a given number of constraints. The general educational timetabling problems commonly refer to both course and examination timetabling which are different in nature. In the examination timetabling, one goal is to spread the different exams for each student as evenly as possible, while in course timetabling the students want an as compact timetable as possible (Causmaeeker, P.D. ,2009). This paper studies a class of educational timetabling problems, known as the polytechnic course timetabling problem (PCTP). It has always been a difficult task for academic offices at higher Institutions each semester to manage this problem. The job of course allocation/ arrangement is a complex system in which various issues must be considered.

The scheduling involves two decision dimensions: teacher assignment and class scheduling. The teacher assignment is to specify which teachers will teach what courses. The class scheduling determines each course will present in which class. The decisions must be taken so as to satisfy a given set of constraints. It should consider teacher's professional knowledge and qualifications, teacher preferences (such as their preferred courses, days and time periods and class), fair distribution of overtime among the teachers, student requests, expectations in class offerings, curriculum planning policies of the school and school's available equipment and facilities . Any conflict with lecturer schedules and class rooms is also avoided. All these issues make the problem very hard to solve in real world circumstances (MirHassani, S. A., 2006). Many types of timetabling problems are NP-Hard problems characterized by some complex constraints (Cooper and Kingston 1997). The constraints that contribute to the complexity of PCSP can be divided into categories; hard and soft (Shaiu, D. F., 2011). For a timetable to be feasible .all the hard constraints must be satisfied. An example of a hard constraint is that no student should be required to simultaneously sit two classes. On the 
DOI: https://dx.doi.org/10.26808/rs.ca.i10v5.02

International Journal of Computer Application (2250-1797)

Issue 10 Volume 5, September- October 2020

other hand, soft constraints are requirements that are not essential but should be held as far as possible (soft constraints can be contravened if necessary). Therefore, soft constraints are sometimes referred as preferences; and they are to evaluate the quality of the solutions.For example, a common soft constraint is to evenly spread classes to the best possible extent. The overall objective is to find a feasible timetable that satisfies all the hard constraints to maximize the satisfaction of lecturers, technologists and classes based on their preferences(or minimize the violation of the soft constraint).

The timetabling problem, like many others in the area of combinatorial optimization, has been approached by several well-known techniques of the operational research and the computer science fields. Several surveys on course timetabling (M.W., Carter, 1998) and automated timetabling (Schaerf, A, 1999), as well as others on more focused aspects of the problem, have managed to record this work in a systematic way, categorizing thus the different variations of the problem and solution approaches. Given the aforementioned work, this paper point out the main contributions of our work with respect to other integer programming formulations . The PCTP can totally differ from one polytechnic to another. Every polytechnic has a unique set of requirements in order to effectively utilize their resources, meet the requirements of their business, and provide a high level of satisfaction to their students.

\section{Methodology}

IP and MIP formulations have started to begin again an acceptable approach in recent years for many combinatorial problems (Johnson, E. L., 2000). The new technologies in information systems, the availability of reliable to solve relatively large problems in relatively short time are the main reasons for making this traditional modelling approach attractive for the solution of realistic problems. IP models have been presented in (Dimopoulou, M, 2001 ) for the university timetabling problem and in (Birbas, T, 1999) for school timetabling problem; the solutions produced with commercial software presented no real problem in terms of computational times.

A university timetabling problem which was adopted for the polytechnic timetabling problem is modelled as an optimization problem using 0-1 variables. The model provides constraints for a large number of different rules and regulations that exist in academic environments. The model succeeds in creating timetables that are free from collisions between courses, lecturers and classrooms and they are complete from all aspects; moreover, it supports the scheduling of courses that require conservative time periods, as well as courses that require sessions that are repeated several times to accommodate different groups of students .

The IP formulation followed in this paper is a novel one and the model carries certain unique features compared to others. The binary variables are defined in such a way that the structural elements: courses, students, teachers, days and periods are preserved in the model in distinct way. This choice was made knowing that in reality the assignment is performed between the set of triplets( courses, teacher, group of students) and the set of pairs(period, day). This leads to a very large number of possible variables, however, with the introduction of suitable subsets of the basic sets of days, time periods, groups of students, teachers, courses and classrooms, this number reduces to manageable sizes.

The emphasis of the paper is on modelling the problem using IP, however, the models that resulted from the real-world problem in our case study were still solvable by commercial packages using the classical branch-and-bound approach.

\section{Problem Formulation}

A mathematical model was formulated for Department of Mathematics, Federal Polytechnic of Ado-Ekiti. Mathematical models were only used to express all the characteristics of a 
DOI: https://dx.doi.org/10.26808/rs.ca.i10v5.02 International Journal of Computer Application (2250-1797) Issue 10 Volume 5, September- October 2020

problem. If the problem is NP-hard, solving the mathematical model is not an effective solution method. Moreover, the mathematical model is a starting point in other solution algorithms such as branch and bound, and their performance highly depends on the effectiveness of the model. All these reasons together show the importance of the model. Timetabling problems are commonly formulated by integer linear programming models. The proposed mathematical model is described in the following sections. The notations and parameters used in both models are as follows.

The PCTP consists of a set of $m$ courses, a set of $n$ lecturers and a set of e classrooms and $f$ laboratories. They should be scheduled in d days and on each day, there are time periods.In each time period, one course can be executed at each classroom. Each lecturer has his own preference to teach each course among the courses of his expertise. Each course can be executed only in a subset of classrooms and a subset days. The objective is to maximize the preference of lecturers and minimize the number of used classrooms. The following parameters and indices are established.

Table 1

Decision Varibales

\begin{tabular}{|l|l|}
\hline $\mathrm{n}$ & The number of lecturers \\
\hline $\mathrm{m}$ & The number of courses \\
\hline $\mathrm{e}$ & The number of classrooms \\
\hline $\mathrm{f}$ & The number of laboratories \\
\hline $\mathrm{d}$ & The number of days \\
\hline $\mathrm{k}$ & Index for working days $\{1,2, \ldots, \mathrm{d}\}$ \\
\hline $\mathrm{g}$ & Index for courses where $\{1,2, \ldots, \mathrm{m}\}$ \\
\hline $\mathrm{i}$ & Index for lecturers where $\{1,2, \ldots, \mathrm{n}\}$ \\
\hline $\mathrm{w}$ & Index for classrooms $\mathrm{w}=\{1,2, \ldots, \mathrm{e}\}$ \\
\hline $\mathrm{l}$ & Index for laboratories $\{1,2, \ldots, \mathrm{f}\}$ \\
\hline $\mathrm{t}$ & Index for time period $\mathrm{t}=\{1,2,3\}$ \\
\hline $\mathrm{P}_{\mathrm{I}, \mathrm{g}}$ & The preference for lecturer $\mathrm{i}$ for teaching course $\mathrm{g}$ \\
\hline $\mathrm{P}_{\mathrm{i}, \mathrm{k}}$ & The preference for lecturer I for being invited on a day $\mathrm{k}$ \\
\hline $\mathrm{P}_{\mathrm{g}, \mathrm{k}}^{3}$ & The preference of course $\mathrm{g}$ for being presented on day $\mathrm{k}$ \\
\hline $\mathrm{X}_{\mathrm{i}, \mathrm{k}}$ & Parameter taking value 1 if lecturer I can be invited on day $\mathrm{k}$, and 0 otherwise \\
\hline $\mathrm{Y}_{\mathrm{i}, \mathrm{g}}$ & Parameter taking value 1 if lecturer I can teach course $\mathrm{g}$, and 0 otherwise \\
\hline $\mathrm{Z}_{\mathrm{g}, \mathrm{i}}$ & $\begin{array}{l}\text { Parameter taking value } 1 \text { if course } \mathrm{g} \text { can be presented in classroom } \mathrm{w}, \text { and } 0 \\
\text { otherwise }\end{array}$ \\
\hline
\end{tabular}

$\mathrm{C}_{\mathrm{i}, \mathrm{g}, \mathrm{k}, \mathrm{w}, \mathrm{t}}$ Binary variable taking value 1 if lecturer $\mathrm{i}$ teaches course $\mathrm{g}$ on day $\mathrm{k}$ in classroom $\mathrm{w}$ in time period $t$, and 0 otherwise

$\mathrm{X}_{\mathrm{i}, \mathrm{k}} \quad$ Binary variable taking value 1 if lecturer $\mathrm{I}$ is invited on a day $\mathrm{k}$, and 0 otherwise.

Maximize : $\mathrm{f}(\mathrm{x})=\sum_{i=1}^{n} \sum_{k=1}^{d} X_{j, k} \cdot p_{l, g}{ }^{1}+\sum_{i=1}^{n} \sum_{j=1}^{m} \sum_{k=1}^{d} \sum_{t=1}^{3} Z_{i, g, k, w, t} \cdot p_{i, k}{ }^{2}+$ $\sum_{i=1}^{n} \sum_{j=1}^{m} \sum_{k=1}^{d} \sum_{i=1}^{e} \sum_{t=1}^{3} Z_{i, g, k, w, t} \cdot p_{g, k}{ }^{3}$ (1)

Objective function which calculates the total utility.

Subjected to:

$$
\sum_{i=1}^{n} \sum_{k=1}^{d} \sum_{l=1}^{e} \sum_{t=1}^{3} C_{i, g, k, w, t}=1
$$

Constraints set that ensures that each course is presented 


$$
\sum_{j=1}^{m} \sum_{l=1}^{e} C_{i, g, k, w, t} \leq X_{i, k} \quad \forall_{i, k, t}
$$

Constraint set that determines the days a lecturer has courses to teach.

$$
X_{i, k} \leq a_{i, k} \quad \forall{ }_{i, k}
$$

Constraints set limits lecturers' course to the days they prefer.

$$
\sum_{i=1}^{n} \sum_{j=1}^{m} Z_{i, j, k, l, t} \leq 1 \quad \forall_{i, k, t}
$$

Constraint set that every lecturer be assigned at most one course, one group of students and one classroom at a time i.e avoids cross assignment.

$$
\sum_{k=1}^{d} \sum_{l=1}^{e} \sum_{t=1}^{3} C_{i, g, k, w, t} \leq b_{i, j} \quad \forall_{i, j}
$$

Constraint set specifies that lecturer is assigned to courses that he/she can teach.

$$
\sum_{i=1}^{n} \sum_{k=1}^{d} \sum_{t=1}^{3} C_{i, g, k, w, t} \leq d_{i, j} \quad \forall_{g, k}
$$

Constraint set ensures that each course is assigned to classes having necessary equipment.

$$
\sum_{j=1}^{m} \sum_{k=1}^{d} \sum_{t=1}^{3} C_{i, g, k, w, t} \leq s_{i, j} \quad \forall_{j, k}
$$

Constraint set that each course should be scheduled for as many teaching periods as the curriculum of each group of students.

$$
\begin{gathered}
X_{i, k} \in\{0,1\} \forall_{i, k} \\
C_{i, g, k, w, t} \in\{0,1\} \forall_{i, g, k, w, t}
\end{gathered}
$$

Constraint set (9) and (10) define the decision variables.

\subsection{Rules of timetabling in the Polytechnic}

Timetable for an institution is a tedious process that administrators usually undertake after spending several man-hours. In this effort timetablers follow several rules, some of which are so important that they may never be violated (hard constraints) and others that are not as important and usually are obeyed only if all hard constraints are satisfied and there is still room for better solutions under some objectives for improved quality (soft constraints).

1. A timetable has to be complete when all courses appear in the timetable.

2. Two or more courses should not be scheduled at the same period for the same lecturers.

3. The timetable has to be able to schedule a given course in any scheme that the responsible lecturer may choose to follow.

4. A timetable should accommodate requests for repetitive sessions of a given course.

5. Preferences for lecturers in specific time intervals are obeyed if possible.

6. Minimize classroom changeovers especially for students of lower-grade years.

7. A timetable should avoid lectures during the special periods such as Juma'ah service periods and lunch.

8. A timetable should avoid periods already pre-assigned to borrowed courses from other schools.

9. Minimize the utilization of early morning and late evening lectures.

\subsection{Determination of cost coefficients}

In any given timetabling problem the cost coefficients in the objective function shown in Eq. (1) may take any value. In fact, if all cost coefficients take the same value, then the 
DOI: https://dx.doi.org/10.26808/rs.ca.i10v5.02 International Journal of Computer Application (2250-1797) Issue 10 Volume 5, September- October 2020

problem becomes degenerate and all feasible solutions will be optimal. In all practical situations this, of course, is not possible and a more specific analysis for the correct assignment of the cost coefficients is needed. While rules for assigning costs to time periods may be the subject of further research, in our model the cost coefficients are assigned values in such ways as to reflect preferences for specific time periods of the day for all courses and for all courses and for specific days of the week for the courses with multiple time periods sessions. Preference for certain classrooms is also incorporated in the $C_{i, g, k, w, t}$ cost coefficients of the objective function.

\subsection{Case Study}

The department of Mathematics and Statistics at the Federal Polytechnic Ado-Ekiti, Ekiti State, Nigeria was chosen. The department which is one of the largest departments in the School of Science and Computer Studies has a two-year programme for Ordinary National Diploma (OND) and a two-year programme for Higher National Diploma (HND) for its students. The department comprise of two units, Statistic unit and Mathematics unit. For the first semester, the department offers a total of 55 courses, summing up to 107 teaching periods for lectures and practical. The department assigns these courses to 5 chief lecturers and 19 lecturers with 6 additional adhoc staffs in both units.

The department disposes 4 regular classrooms (suitable for lectures) and 6 specialized laboratories. The regular classes are often share by sisters department when no lectures are taking on in the classes. Classrooms have variable capacities and are suitable either for large or small students.

An IP model based on the formulation described in this paper was developed for the construction of the first semester timetable. The cost coefficients were assigned values according to the strategy discussed earlier, using functions similar to the in Fig 1. The mixed integer programming solver CPLEX 5.1 was used in an HP J7OOO Workstation and the solution found is a proposed timetable for the department.

Discussion on the resulting timetables

Curriculum for both ND and HND in the Department of Mathematics and Statistics

Students have to take all the compulsory courses and practical's before graduating for Ordinary National Diploma or Higher National Diploma. The course title, course code, structure(lectures/lab work), and the assigned time periods, as well as the groups for the lab work are all presented in the Table 2.

Table 2

\begin{tabular}{|l|l|l|l|l|l|l|l|}
\hline $\begin{array}{l}\text { ND } \\
\text { I }\end{array}$ & & & & ND II & & & \\
\hline No & Course Title & Code & Unit & No & Course Title & Code & Unit \\
\hline 1 & Citizenship Education & GNS 127 & 2.0 & 1 & Industrial Statistics I & $\begin{array}{l}\text { STA } \\
214\end{array}$ & 2.0 \\
\hline 2 & Logic and Linear Algebra & $\begin{array}{l}\text { MTH } \\
111\end{array}$ & 2.0 & 2 & Technical English II & $\begin{array}{l}\text { OTM } \\
212\end{array}$ & 2.0 \\
\hline 3 & Intro. to Entrepreneurship & EED 116 & 2.0 & 3 & $\begin{array}{l}\text { Economics \& Social } \\
\text { Statistics 1 }\end{array}$ & STA 213 & 2.0 \\
\hline 4 & Technical English I & STA 123 & 2.0 & 4 & $\begin{array}{l}\text { Mathematical Method } \\
\text { MTH }\end{array}$ & 2.0 \\
\hline 5 & Intro. To Computer & $\begin{array}{l}\text { COM } \\
101\end{array}$ & 3.0 & 5 & $\begin{array}{l}\text { Practice of } \\
\text { Entrepreneurship }\end{array}$ & EED 216 & 2.0 \\
\hline 6 & Elementary Prob. Theory & STA 112 & 3.0 & 6 & $\begin{array}{l}\text { Linear Algebra } \\
\text { MTH }\end{array}$ & 2.0 \\
\hline
\end{tabular}


DOI: https://dx.doi.org/10.26808/rs.ca.i10v5.02

International Journal of Computer Application (2250-1797)

Issue 10 Volume 5, September- October 2020

\begin{tabular}{|c|c|c|c|c|c|c|c|}
\hline 7 & Descriptive Statistics & STA 111 & 3.0 & 7 & Statistical Packages I & $\begin{array}{l}\text { COM } \\
215\end{array}$ & 2.0 \\
\hline 8 & Intro. to Programming & $\begin{array}{l}\mathrm{COM} \\
113\end{array}$ & 3.0 & 8 & Statistical Theory II & STA 211 & 3.0 \\
\hline 9 & Functions and Geometry & $\begin{array}{l}\text { MTH } \\
112\end{array}$ & 3.0 & 9 & $\begin{array}{l}\text { Element of Sampling } \\
\text { theory }\end{array}$ & STA 212 & 4.0 \\
\hline 10 & & ICT & 0 & & & ICT & 0 \\
\hline $\begin{array}{l}\text { HND } \\
\text { I }\end{array}$ & & & & $\begin{array}{l}\text { HND } \\
\text { II }\end{array}$ & & & \\
\hline No & Course Title & Code & Unit & No & Course Title & Code & Unit \\
\hline 1 & Statistical Theory III & STA 311 & 3.0 & 1 & $\begin{array}{l}\text { Design \& Analysis of } \\
\text { Expt. II }\end{array}$ & STA 417 & 3.0 \\
\hline 2 & Technical English II & $\begin{array}{l}\text { OTM } \\
315\end{array}$ & 2.0 & 2 & $\begin{array}{l}\text { Economics \& Social } \\
\text { Statistics II }\end{array}$ & STA 414 & 3.0 \\
\hline 3 & $\begin{array}{l}\text { Stat. Inference \& } \\
\text { Scientific Methods }\end{array}$ & STA 313 & 2.0 & 3 & Industrial Statistics II & STA 416 & 2.0 \\
\hline 4 & Mathematical Methods II & $\begin{array}{l}\text { MTH } \\
314\end{array}$ & 3.0 & 4 & $\begin{array}{l}\text { Operational Research } \\
\text { II }\end{array}$ & STA 411 & 3.0 \\
\hline 5 & Operational Research I & STA 314 & 3.0 & 5 & Sampling Tech. II & STA 412 & 3.0 \\
\hline 6 & Applied General Stat. II & STA 312 & 3.0 & 6 & $\begin{array}{l}\text { Entrepreneurship } \\
\text { Development II }\end{array}$ & EED 416 & 2.0 \\
\hline 7 & Database Design I & $\begin{array}{l}\mathrm{COM} \\
312\end{array}$ & 3.0 & 7 & Industrial Statistics II & STA 415 & 3.0 \\
\hline 8 & $\begin{array}{l}\text { Entrepreneurship } \\
\text { Development }\end{array}$ & EED 316 & 2.0 & 8 & Econometrics & STA 413 & 3.0 \\
\hline 9 & & ICT & 0 & 9 & & ICT & 0 \\
\hline 10 & & & & 10 & $\begin{array}{l}\text { Small Business } \\
\text { Management }\end{array}$ & STA 418 & 2.0 \\
\hline
\end{tabular}

Table 3

\begin{tabular}{|l|l|l|l|l|l|l|}
\hline & CLASS & $\mathbf{8 . 0 0 - 1 0 . 0 0 A M}$ & $\begin{array}{l}\mathbf{1 0 . 0 -} \\
\mathbf{1 2 . 0 0 A M}\end{array}$ & $\mathbf{1 2 . 0 0 - 2 . 0 0 P M}$ & $\begin{array}{l}\mathbf{2 . 0 0 -} \\
\mathbf{4 . 0 0 P M}\end{array}$ & $\begin{array}{l}\mathbf{4 . 0 0}- \\
\mathbf{6 . 0 0 P M}\end{array}$ \\
\hline MONDAY & ND I & GNS 127 & MTH 111 & STA 112 P & & \\
\hline & ND II & & ICT & OTM 212 & STA 211 P & \\
\hline & HND I & STA 311 & STA 314 & ICT & OTM 315 & \\
\hline & HNDII & & STA 417 & STA 414 & STA 417P & \\
\hline & & & & & & \\
\hline TUESDAY & ND I & EED 116 & STA 123 & COM 102 & ICT & \\
\hline & ND II & STA 214 & STA 213 & MTH 212 & STA 214P & \\
\hline & HND I & STA 313 & MTH 314 & STA 314 & STA 311P & \\
\hline & HNDII & STA 416 & STA 411 & STA 412 & STA 411P & STA 414P \\
\hline & & & & & & \\
\hline WEDNESDAY & ND I & STA 112 & STA 111 & COM 113 & & \\
\hline & ND II & EED 216 & MTH 213 & COM 215 & STA 213P & \\
\hline & HND I & & STA 312 & COM 312 & STA 313P & \\
\hline & HNDII & EED 416 & STA 415 & STA 413 & & \\
\hline & & & & & & \\
\hline
\end{tabular}


DOI: https://dx.doi.org/10.26808/rs.ca.i10v5.02

International Journal of Computer Application (2250-1797)

Issue 10 Volume 5, September- October 2020

\begin{tabular}{|l|l|l|l|l|l|l|}
\hline THURSDAY & ND I & & & STA IIIP & & \\
\hline & ND II & & STA 212P & STA 212 & & \\
\hline & HND I & EED 316 & & STA 312P & & \\
\hline & HNDII & STA 418 & STA 416P & ICT & STA 413P & STA 415P \\
\hline & & & $\begin{array}{l}10.00- \\
12.00 \mathrm{PM}\end{array}$ & $12.0-1.00 \mathrm{AM}$ & $\begin{array}{l}1.00- \\
2.00 \mathrm{PM}\end{array}$ & $\begin{array}{l}2.00- \\
4.00 \mathrm{PM}\end{array}$ \\
\hline & & & & Break & \\
\hline FRIDAY & ND I & MTH 112 & & & Break & \\
\hline & ND II & & & & Break & \\
\hline & HND I & & & & Break & \\
\hline
\end{tabular}

\section{P- PRACTICAL}

The following should be noted from the above Table:

(i) All courses required by the curriculum appear in the timetable with no conflicts among them. Since all students have to take the compulsory courses, there no overlapping between courses.

(ii) Each courses appears in so many periods as required from the curriculum, assigning lectures and recitations in regular classrooms (indicated as $\mathrm{C \# )}$ an practical work in laboratories (indicated as LR\#)

(iii) All lectures for mandatory courses are scheduled during morning sessions (8:00-6:00) following the preferences for certain time periods given as input from the timetable.

(iv) Lab work is scheduled around afternoon, for various reasons that the timetable thought would be beneficial to the students.

(iv) Break is only honour on Fridays due to Muslim Juma'ah Service between the period of (1.00-2.00PM).

Table 5

Size of problems solved and resulting models

\begin{tabular}{|l|l|l|l|l|l|l|l|}
\hline & $\begin{array}{l}\text { No of } \\
\text { courses }\end{array}$ & $\begin{array}{l}\text { No of lab } \\
\text { courses }\end{array}$ & $\begin{array}{l}\text { Required } \\
\text { teach. per. }\end{array}$ & $\begin{array}{l}\text { No of } \\
\text { rooms/Labs }\end{array}$ & $\begin{array}{l}\text { No or } \\
\text { rows }\end{array}$ & $\begin{array}{l}\text { No of } \\
\text { columns }\end{array}$ & $\begin{array}{l}\text { No, of } \\
\text { Non-zeros }\end{array}$ \\
\hline Problem \#1 & 20 & 6 & 66 & $4 / 2$ & 1,943 & 1,267 & 10,685 \\
\hline Problem \#2 & 25 & 8 & 83 & $5 / 2$ & 3,658 & 1,546 & 15,523 \\
\hline
\end{tabular}

Computational Results

In order to evaluate the proposed IP model, two problems of different size were solved and are exposed in Table 5. The number of courses varied from 20 to 25 in addition to lab courses that varied from 6 to 6 totalling the requirements for teaching periods 66 to 83 . We should note that these teaching periods scheduled within the 107 available time periods for a week.

The models that resulted following the suggested IP formulated carried 1,943-3,658 equations and 1,267-1,546 binary variables, while the non-zeros of the IP model varied from 10,685-15,523. Computing the optimal timetables required 1 minutes for the first problem, 3 minutes for the latter one. It is important to mention the role of the values chosen for the cost coefficients. Changing the penalty functions will results to change in computation time by a large factor, meaning that the optimization process may be guided faster to the optimal solution.

\section{Summary and Conclusions}

In this research, IP formulation of a timetabling problem as it appears in many polytechnics, adding however many features that may be distinct in Department of 
DOI: https://dx.doi.org/10.26808/rs.ca.i10v5.02 International Journal of Computer Application (2250-1797) Issue 10 Volume 5, September- October 2020

Mathematics and Statistics, Federal Polytechnic Ado-Ekiti. The problem is hard one and very complex, however, the choices made through the modelling process result to solvable and flexible models.

A variety of rules may be represented in the model with suitable constraints provided by IP formulation model. The choice made for the cost function allows the introduction of certain prefernces regarding time periods, days and classrooms, so that the timetables can be improved according to well-accepted quality measures.

The timetable for the Department of Mathematics and Statistics in our polytechnic was adopted as a case study and was solved very successfully. The timetable construction required scheduling of lectures and lab courses, each type carrying different characteristics and request. Creating timetables for academic institutions requires a tedious process, however, automation is now possible.

\section{References}

1. Causmaeeker, P.D., Demeester P., and Varden Bergh.G. (2009)." A decomposed metaheuristic approach for a real-world university timetabling problem' European Journal of Operational Research, 195, pp.307-318.

2. Cooper, T. B. and Kingston, J. H. (1996)." The complexity of timetabling construction problems'. Springer Lecture Note in Computer Science.1153:283-295.

3. E.L. Johnson, G. L. Nemhauser, M.W.P. Savelsbergh (2000). Progress in linear programming based branch-and-bound algorithm: An exposition. INFORMS Journal on Computing 12.

4. M. Dimopolou, P. Miliotis, Implementation of a university course and examination timetabling system. European Journal of Operational Research 130 (2001) 202-213.

5. MirHassani, S. A., and Habibi, F., (2013). Solution approaches to the course timetabling problem, Artificial Intelligence Review 39, pp. 133-149.

6. MirHassani, S.A.(2006).' A computational approaches to enhancing course timetabling with Integer programming', Applied mathematics and computation, 175, pp.814-822.

7. M. W., Carter, G. laporte,(1998). Recent developments in practical coursescheduling ,in E. Burke M. Carter (Eds). Practice and theory of timetabling II, Springer.Verlag, pp 3-19.

8. Schaerf, A. (1999). A survey of automated timetabling Artificial Intelligence Review 13(2), 81-127.

9. Shiau , D. F. (2011). " A hybrid particle swarm optimization for a university course scheduling problem with flexible preferences', Expert systems with Applications, 38 pp. 235-248.

10. T. Birbas, S. Daskalaki, E. Housos (1997). Course and teacher scheduling in Hellenic high schools, in : 4th Balkan Conference on Operational Research , Thessaloniki, Greece.

11. T. Birbas, S. Daskalaki, E. Housos (1997). Timetabling for Greek high schools, Journal of OperationalSociety 48,1191-1200.

12. Turabieh, H., Abdullah, S. (2011). " An integrated Hybrid approach to the examination timetabling problem', omega, 39, pp. 598-607. 